\title{
Effects of IL-6 on pyruvate dehydrogenase regulation in mouse skeletal muscle
}

\author{
Rasmus S. Biensø • Jakob G. Knudsen • Nina Brandt • \\ Per A. Pedersen • Henriette Pilegaard
}

Received: 26 June 2013 / Revised: 28 October 2013 / Accepted: 29 October 2013 / Published online: 14 November 2013

(C) The Author(s) 2013. This article is published with open access at Springerlink.com

\begin{abstract}
Skeletal muscle regulates substrate choice according to demand and availability and pyruvate dehydrogenase $(\mathrm{PDH})$ is central in this regulation. Circulating interleukin (IL)-6 increases during exercise and IL-6 has been suggested to increase whole body fat oxidation. Furthermore, IL-6 has been reported to increase AMP-activated protein kinase (AMPK) phosphorylation and AMPK suggested to regulate PDHa activity. Together, this suggests that IL-6 may be involved in regulating PDH. The aim of this study was to investigate the effect of a single injection of IL-6 on PDH regulation in skeletal muscle in fed and fasted mice. Fed and 16-18 $\mathrm{h}$ fasted mice were injected with either $3 \mathrm{ng} \cdot \mathrm{g}^{-1} \mathrm{re}-$ combinant mouse IL-6 or PBS as control. Fasting markedly reduced plasma glucose, muscle glycogen, muscle PDHa activity, as well as increased PDK4 mRNA and protein content in skeletal muscle. IL-6 injection did not affect plasma glucose or muscle glycogen, but increased AMPK and ACC phosphorylation and tended to decrease $\mathrm{p} 38$ protein content in skeletal muscle in fasted mice. In addition IL-6 injection reduced PDHa activity in fed mice and increased PDHa
\end{abstract}

R. S. Biens $\varnothing \cdot$ J. G. Knudsen · N. Brandt • H. Pilegaard Centre of Inflammation and Metabolism and The August Krogh

Centre, University of Copenhagen, Copenhagen, Denmark

R. S. Biensø • J. G. Knudsen • N. Brandt • P. A. Pedersen •

H. Pilegaard

Department of Biology, University of Copenhagen, Copenhagen,

Denmark

H. Pilegaard $(\bowtie)$

Universitesparken 13, 2100 Copenhagen Ø, Denmark

e-mail: hpilegaard@bio.ku.dk

Present Address:

N. Brandt

Exercise and Metabolic Disease Research Laboratory, Translational

Sciences Section, School of Nursing, University of California, Los

Angeles, CA, USA activity in fasted mice without significant changes in $\mathrm{PDH}-$ E1 $\alpha$ phosphorylation or PDP1 and PDK 4 mRNA and protein content. The present findings suggest that IL- 6 contributes to regulating the PDHa activity and hence carbohydrate oxidation, but the metabolic state of the muscle seems to determine the outcome of this regulation. In addition, AMPK and p38 may contribute to the IL-6-mediated PDH regulation in the fasted state.

Keywords IL-6 · Pyruvate dehydrogenase activity · AMPK · p38 $\cdot$ Skeletal muscle

\section{Introduction}

Skeletal muscle has an exceptional ability to adjust the substrate choice during fasting and exercise according to the substrate availability [9, 24]. During prolonged exercise, skeletal muscle first oxidizes blood glucose and stored glycogen, but an increasing fraction of the energy is derived from fat oxidation as the exercise proceeds [37, 38]. This ensures that exercise can continue, although at a lower exercise intensity. Similarly, fasting is associated with a switch in substrate oxidation from carbohydrates to fat markedly increasing survival without food intake.

The pyruvate dehydrogenase complex (PDC) is central in the regulation of substrate choice in skeletal muscle. PDC converts pyruvate into acetyl CoA thereby linking glycolysis with the citric acid cycle and represents the only entry for carbohydrate-derived substrate into the mitochondria for oxidation. PDC is composed of several copies of three catalytic enzymes, which includes the pyruvate dehydrogenase (PDH)E1 $\alpha$. Fasting has been shown to downregulate the activity of PDH in the active form (PDHa) [43]. In addition, PDHa activity increases with exercise [37], but declines towards resting level as the exercise duration exceeds $2 \mathrm{~h}[25,39]$. 
Although PDHa activity can be allosterically regulated [2], phosphorylation/dephosphorylation of the $\alpha$ subunit of PDH$\mathrm{E} 1$ is thought to be the main mechanism regulating the activity of PDH. Phosphorylation and concomitant inactivation of $\mathrm{PDH}$ is catalyzed by pyruvate dehydrogenase kinases (PDK), and dephosphorylation and concomitant activation of PDH is catalyzed by pyruvate dehydrogenase phosphatases (PDP). The decrease in PDHa activity during fasting seems to be due to increased PDK4 protein and decreased PDP1 protein content in the muscle [43], while the reduction during prolonged exercise does not appear to be caused by increased PDK4 protein content but may be due to increased PDK activity as previously reported [39]. The underlying mechanisms initiating the regulation of PDH during prolonged exercise remains unresolved.

Interleukin (IL)-6 is a myokine released from contracting muscle during exercise and suggested to exert autocrine, paracrine and endocrine effects [23]. The plasma IL-6 concentration has been reported to increase in both humans and mice during prolonged exercise [20, 21]. In humans, the increase in plasma IL-6 concentration during exercise is detectable after about 2 hour with moderate exercise intensity and increases further with exercise duration [12,34], while an increase in plasma IL-6 has been detected already after $30 \mathrm{~min}$ of intense exercise in mice [20]. Recombinant IL-6 has been shown to increase free fatty acid release from myotubes [1] and increase fat oxidation in human skeletal muscle in vivo $[35,42]$. In addition, IL-6 has been reported to increase AMPactivated protein kinase (AMPK) phosphorylation in rat skeletal muscle [13], and rodent studies suggest that AMPK may regulate PDH [17, 32]. Furthermore, IL-6 has been shown to increase phosphorylation of the stress mitogen activated protein (MAP) kinase p38 in incubated human muscle [6] and MAPK p38 has been demonstrated to be involved in the regulation of IL-6 transcription [36]. Furthermore, previous findings suggest an association between increased p38 phosphorylation and decreased PDHa activity in cardiomyocytes [29]. Together this suggests that IL-6 could be involved in regulating the substrate choice of muscle either by directly regulating PDH or potentially via AMPK and $\mathrm{p} 38$. Therefore, the aim of the present study was to examine the isolated effects of a single injection of recombinant mouse (rm) IL-6 on PDH regulation in mouse skeletal muscle. As IL-6 normally is elevated during exercise in the presence of severe metabolic challenge, the effect of IL-6 injection was determined in both the fed and fasted state.

\section{Methods}

Mice Female C57BL/6 mice (Taconic, Lille Skensved, Denmark) 8 weeks of age were used in the study. Female mice were used because a previous study showed no indications of gender-specific regulation of PDH [14] and because regular oestrous cycle has been reported to be absent in the majority of female mice housed in large groups [41]. The mice had ad libitum access to water and normal chow diet (Altromin 1324, Brogaarden, Lynge, Denmark) and had a 12:12 light-dark cycle. The experiments were approved by the Danish Animal Experimental expectorate (license no. 2009, 561 1607) and complied by the European Convention for the protection of vertebrate animals used for experiments and other scientific purpose (Council of Europe no. 123. Strasbourg, France 1985).

Experimental setup The mice were housed individually $24 \mathrm{~h}$ before initiation of the experiment and divided into two groups either fed or fasted for 16-18 h. The mice were given an intraperitoneal injection of either phosphate-buffered saline (PBS) or rm IL-6 $\left(3 \mathrm{ng} \cdot \mathrm{g}^{-1}\right)$ dissolved in PBS. The mice were euthanized by cervical dislocation 30 or $60 \mathrm{~min}$ after the injection. Quadriceps muscles were removed and frozen in liquid nitrogen. Trunk blood was collected in EDTA containing tubes and plasma was collected after centrifugation at $2,600 \times \mathrm{g}$, $15 \mathrm{~min}, 4^{\circ} \mathrm{C}$. Muscle and plasma samples were stored at $-80^{\circ} \mathrm{C}$.

Plasma glucose and plasma IL-6 Plasma glucose concentration was analyzed fluorometrically [18]. The plasma IL-6 concentration was determined using Meso Scale Discovery (Rockville, MD, USA) as described by the manufacturer.

Muscle glycogen Muscle samples were hydrolyzed in $1 \mathrm{M}$ $\mathrm{HCl}$ and the muscle glycogen concentration was determined fluorometrically as glycosyl units as previously described [22].

RNA isolation and reverse transcription Quadriceps muscles from the mice were crushed in liquid nitrogen to ensure homogeneity of each sample. RNA was isolated using a guanidinium thiocyanate phenol-choloroform method as previously described $[4,26]$ except that the samples were homogenized using a Tissue LyserII (Qiagen, Hilden, Germany). Reverse transcription was performed using the Superscript II RNase $\mathrm{H}^{-}$system (Invitrogen, Carlsbad, CA, USA) as previously described [26].

Real time PCR mRNA content was determined by use of the $5^{\prime}$ fluorogenic nuclease assay with TaqMan probes (ABI PRISM 7900 Sequence Detection System; Applied Biosystems, Foster City, CA, USA) as previously described [19]. Primer and probe sequences are given in Table 1. Cycle threshold values reflecting the content of a specific mRNA were converted to an arbitrary amount by use of a standard curve, constructed from a serial dilution of a representative sample run together with the unknown samples. For each sample the amount of target cDNA was normalized to the total single stranded (ss)DNA content in the sample determined by OliGreen as previously described [19]. 


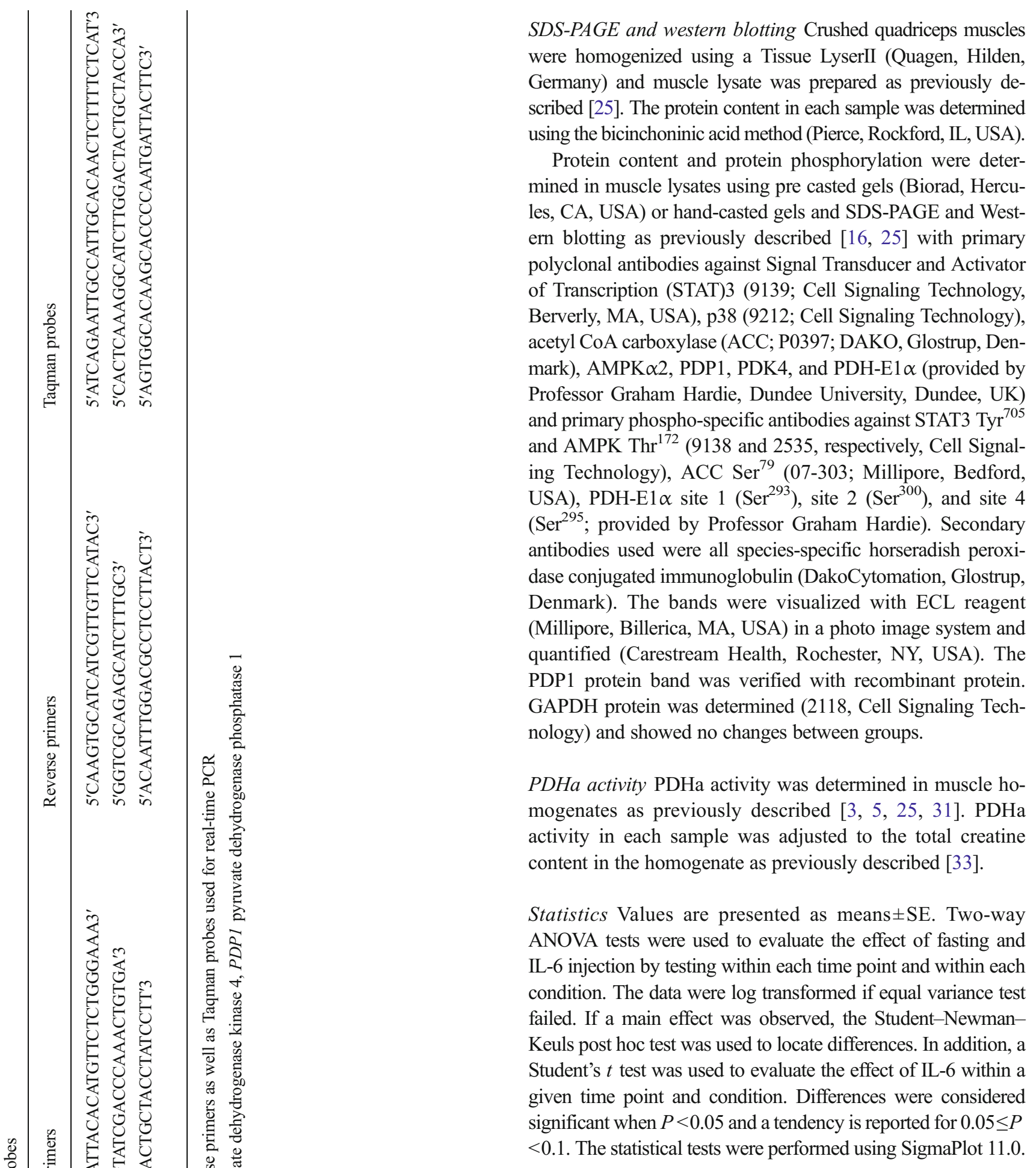

\section{Results}

Plasma IL-6

The plasma IL- 6 concentration was measured to examine the time course of plasma IL- 6 after an IL-6 injection. The IL-6 
injection increased $(P<0.05)$ the plasma IL-6 concentration 9.5-fold in fed mice and 40-fold in fasted mice $30 \mathrm{~min}$ after the injection relative to the PBS injected mice. After $60 \mathrm{~min}$, the plasma IL-6 concentration was still elevated $(P<0.05) 5$-fold in fed mice and 12 -fold in fasted mice relative to the PBSinjected mice (Fig. 1a).

In the IL-6-injected mice, the plasma IL-6 level was 2.4fold higher $(P<0.05)$ in fasted than fed mice at $30 \mathrm{~min}$, which may be due to differences in blood volume or differences in uptake or removal of IL-6 from the blood. In the PBS-injected mice, fasting reduced $(P<0.05)$ the plasma IL- 6 concentration to $60 \%$ compared with the fed mice (Fig. 1a). However, of notice is that such effect was not present at 30 min suggesting that additional factors have contributed to the effect observed at $60 \mathrm{~min}$ (Fig. 1a).

\section{STAT3 phosphorylation}

STAT3 phosphorylation was determined in skeletal muscle to confirm that IL-6 injections induced IL-6-mediated intracellular responses.

IL-6 injection increased $(P<0.05)$ STAT3 Tyr $^{705}$ phosphorylation in skeletal muscle 2-fold in fed mice and 2.3-fold in fasted mice relative to PBS at $30 \mathrm{~min}$ after injection. At $60 \mathrm{~min}$, the injection of IL-6 increased $(P<0.05)$ the STAT $\mathrm{Tyr}^{705}$ phosphorylation in skeletal muscle 2.2-fold in fed and 2 -fold in fasted mice relative to PBS-injected mice (Fig. 1b).

In the IL-6-injected mice, STAT3 $\mathrm{Tyr}^{705}$ phosphorylation was at $30 \mathrm{~min} 1.8$-fold higher $(P<0.05)$ in the fasted than the fed mice (Fig. 1b).

\section{Plasma glucose}

The blood glucose concentration was measured to describe the metabolic status of the mice during fasting and after IL-6 injection. The IL-6 injection did not change the plasma

glucose concentration relative to PBS, neither in the fed nor the fasted mice (Fig. 2a).

Plasma glucose concentration was at approximately $8 \mathrm{mM}$ in fed mice independent of injection and decreased $(P<0.05)$ to approximately $5 \mathrm{mM}$ in the fasted mice both in the PBS and the IL-6-injected mice (Fig. 2a).

\section{Muscle glycogen}

Muscle glycogen concentration was measured to describe the metabolic status of the mice during fasting and after IL-6 injection. There was a main effect $(P<0.05)$ of IL-6 injection on muscle glycogen content at $30 \mathrm{~min}$, but no changes were observed at $60 \mathrm{~min}$ (Fig. 2b).

Fasting reduced $(P<0.05)$ the muscle glycogen content with 50-60\% compared with the fed mice independent of injection (Fig. 2b).

\section{Signaling}

AMPK, ACC and p38 phosphorylation were determined to examine the effects of IL-6 on intracellular signaling in skeletal muscle.

\section{$A M P K$}

There were no effects of IL-6 on AMPK Thr ${ }^{172}$ phosphorylation in skeletal muscle of the fed mice. In the fasted mice, the IL-6 injection increased $(P<0.05)$ AMPK Thr ${ }^{172}$ phosphorylation 1.3-fold relative to PBS at 60 min (Fig. 3a).

In addition, at $30 \mathrm{~min}$ fasting tended to increase $(0.05 \leq P<$ $0.1)$ AMPK $\mathrm{Thr}^{172}$ phosphorylation 1.2-fold in the PBSinjected mice and in the IL-6-injected mice fasting increased $(P<0.05)$ AMPK phosphorylation 1.2 -fold relative to fed (Fig. 3a).

Fig. 1 Plasma concentration of IL-6 and STAT3 phosphorylation. Plasma IL-6 concentration (nanograms per milliliter) (a) and STAT3 phosphorylation (b) in fed $(F E D)$ and fasted (FASTED) mice 30 and $60 \mathrm{~min}$ after a single injection of either PBS or rmIL-6. Values are means $\pm \mathrm{SE} ; n=8 . * P<$ 0.05 , significantly different from PBS within given condition and time point; $\# P<0.05$, significantly different from FED within given treatment and time point
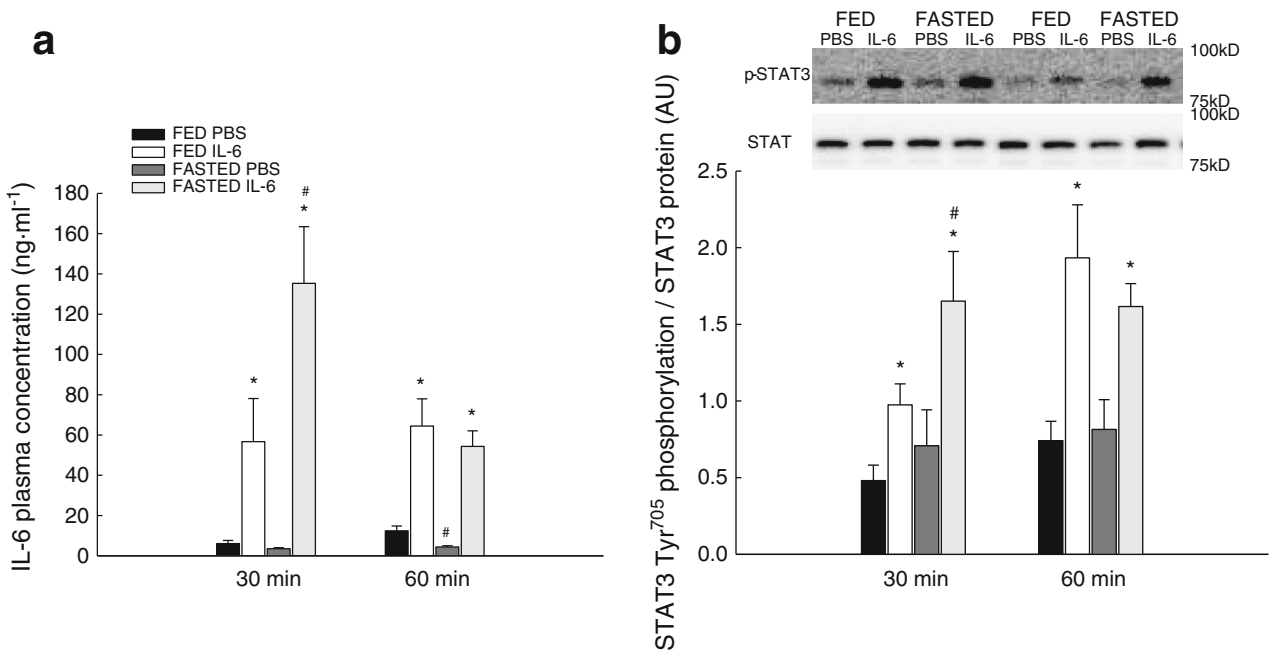


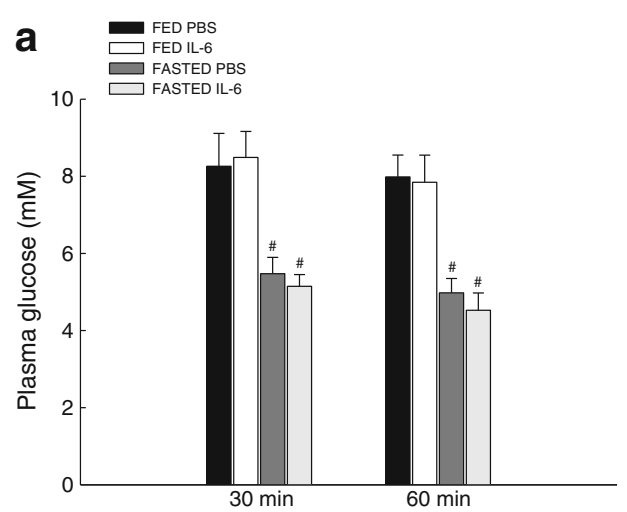

Fig. 2 Plasma glucose concentration and muscle glycogen. Plasma glucose concentration (millimolar) (a) and muscle glycogen (millimoles per kilogram) (b), in skeletal muscle of fed (FED) and fasted (FASTED) mice 30 and 60 min after a single injection of either PBS or rmIL-6. Values are

\section{$A C C$}

The IL-6 injection did not change ACC Ser ${ }^{79}$ phosphorylation in skeletal muscle of the fed mice. In the fasted mice, the IL-6 injection increased $(P<0.05)$ the ACC phosphorylation 1.4fold in the fasted mice relative to the PBS mice at $60 \mathrm{~min}$ when using a $t$ test (Fig. 3b).

In line with the AMPK results, 30 min after injection, ACC $\mathrm{Ser}^{79}$ phosphorylation was 1.5 -fold higher $(P<0.05)$ in fasted than in fed mice injected with PBS and tended to be 1.4-fold higher $(0.05 \leq P<0.1)$ in fasted than in fed mice injected with IL-6 (Fig. 3b).

p38

The IL-6 injection did not change the phosphorylation level of p38 when normalized to p38 protein content in skeletal muscle of fed or fasted mice (Fig. 3c). However, the IL-6 injection tended to decrease $(0.05 \leq P<0.1)$ the $\mathrm{p} 38$ protein content with $70-85 \%$ compared with PBS injection both at 30 and $60 \mathrm{~min}$ (Fig. 3c, d).

In addition, $\mathrm{p} 38$ protein content was 1.5 - to 1.8 -fold higher $(P<0.05)$ in the fasted than the fed mice both at 30 and $60 \mathrm{~min}$ (Fig. 3d).

\section{IL-6 mRNA}

IL-6 injection did not change the mRNA content of IL-6 in skeletal muscle of the fed and fasted mice (Fig. 4).

Furthermore, fasting increased $(P<0.05)$ the IL-6 mRNA level 1.8- to 2.0-fold at 30 and 60 min but only in the IL-6injected mice (Fig. 4).

\section{PDH regulation}

The mRNA and protein levels of PDK4 and PDP1 were determined together with the PDHa activity and PDH b

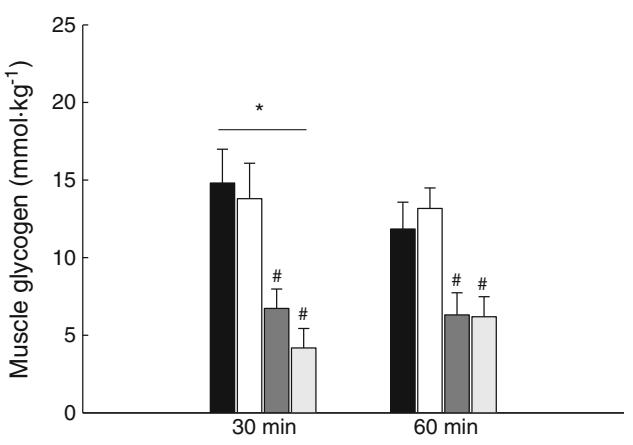

means \pm SE; $n=8$. ${ }^{*} P<0.05$, significantly different from PBS within given condition and time point; $\# P<0.05$, significantly different from FED within given treatment and time point. Line indicates an overall effect

phosphorylation to examine the effects of fasting and IL-6 injection on $\mathrm{PDH}$ regulation.

\section{$P D K 4$ and PDP 1 mRNA}

IL-6 injection did not change the PDK4 mRNA content in skeletal muscle of the fed and fasted mice (Fig. 5a), but the PDP1 mRNA content tended to be higher $(0.05 \leq P<0.1)$ 60 min after IL-6 injection than PBS (Fig. 5c).

Fasting increased $(P<0.05)$ the PDK4 mRNA content 5 - to 6-fold Fig. 5a) and decreased $(P<0.05)$ the PDP1 mRNA content with $60 \%$ (Fig. 5c).

\section{PDK4 and PDP1 protein}

The PDK4 protein content in skeletal muscle increased $(P<$ $0.05)$ 1.6-fold in the fasted mice relative to the fed with no effect of IL-6 injection (Fig. 5b). The PDP1 protein content did not change with IL-6 injection or with fasting (Fig. 5d).

\section{PDHa activity}

The PDHa activity in skeletal muscle tended overall to be lower $(0.05 \leq P<0.1)$ in the IL-6-injected fed mice than the PBS injected fed mice. In addition, the PDHa activity was in the fed mice at 30 min $30 \%$ lower $(P<0.05)$ after IL-6 injection than after PBS when using a $t$ test. IL-6 injection in the fasted mice increased $(P<0.05)$ PDHa activity 2 -fold at $30 \mathrm{~min}$ and 1.8 -fold at $60 \mathrm{~min}$.

Furthermore, fasting overall reduced $(P<0.05)$ the PDHa activity in skeletal muscle to $15-30 \%$ of the level in fed mice (Fig. 6a).

\section{PDH-E1 $\alpha$ phosphorylation}

Overall, the effects on PDH-E1 $\alpha$ phosphorylation were similar for the investigated PDH-E1 $\alpha$ phosphorylation sites. IL-6 

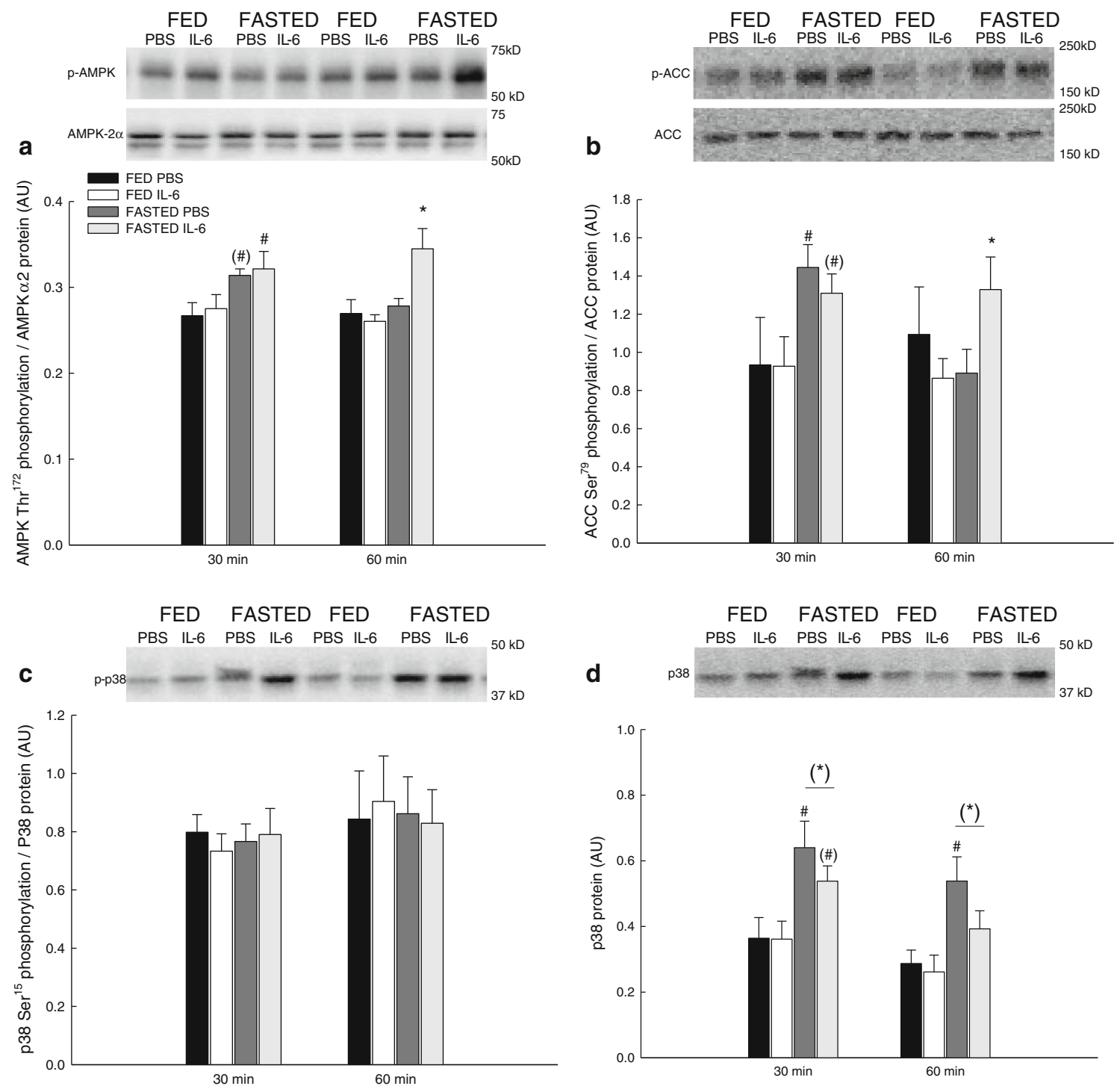

Fig. 3 Phosphorylation of AMPK, ACC, and p38. AMPK Thr ${ }^{172}$ phosphorylation (a), ACC Ser ${ }^{79}$ phosphorylation (b), p38 Ser $^{15}$ phosphorylation (c), and p38 protein content (d) in skeletal muscle of fed (FED) and fasted (FASTED) mice 30 and 60 min after a single injection of either PBS or rmIL-6. Values are means \pm SE; $n=8$. ${ }^{*} P<0.05$, significantly

injection did not change PDH-E1 $\alpha$ phosphorylation in the fed or fasted mice (Fig. 6b-d).

Fasted mice had 1.7- to 2.1-fold higher $(P<0.05)$ PDHE1 $\alpha$ phosphorylation than fed mice independent of injection (Fig. 6b-d).

\section{Discussion}

The main finding of the present study is that IL-6 injections regulated PDHa activity in mouse skeletal muscle but differently in fed and fasted conditions. In addition, an IL-6 injection increased AMPK and ACC phosphorylation in mouse skeletal muscle only in the fasted state. This indicates that

different from PBS within given condition and time point; $\# P<0.05$, significantly different from FED within given treatment and time point. Symbols within parentheses indicate a statistical tendency, $0.05 \leq P<0.1$. Line indicates an overall effect

AMPK did not mediate the IL-6-induced reduction in PDHa activity in the fed state but could potentially be involved in the increase in the fasted state. Furthermore, IL- 6 reduced p38 protein content in skeletal muscle in the fasted state, making it possible that p38 could play a role in the observed IL-6induced change in PDHa activity in the fasted state.

Skeletal muscle regulates substrate choice according to availability and is therefore capable of coping with major metabolic changes during exercise and fasting $[2,38]$. The previous findings that IL-6 infusion in humans enhances fat oxidation in skeletal muscle [35] and that plasma IL-6 is increased during prolonged exercise [21] suggest that IL-6 could be involved in regulating substrate choice during exercise. The observation that the increase in plasma IL-6 after the 


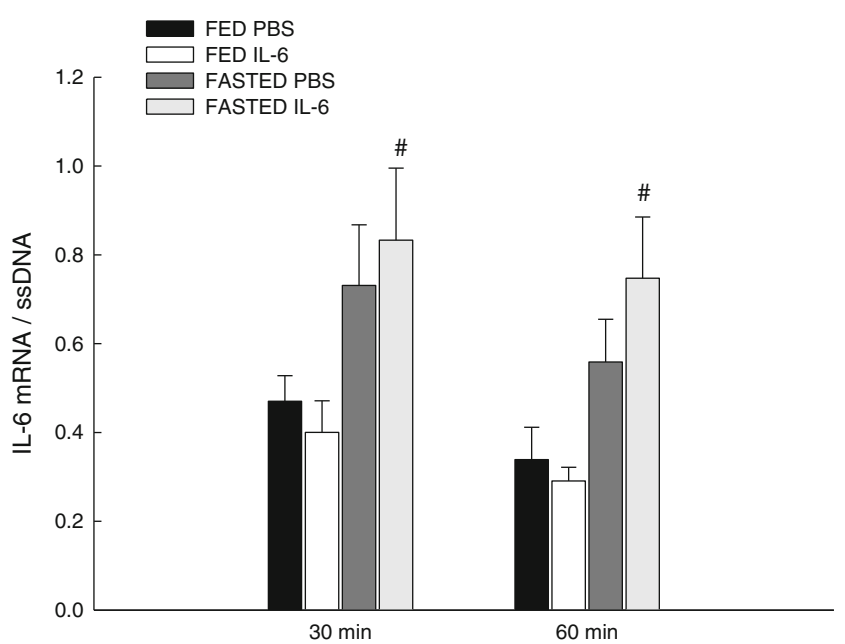

Fig. 4 IL-6 mRNA content. IL-6 mRNA in skeletal muscle of fed (FED) and fasted (FASTED) mice 30 and $60 \mathrm{~min}$ after a single injection of either PBS or rmIL-6. Values are means \pm SE; $n=8$. $\# P<0.05$, significantly different from FED within given treatment and time point
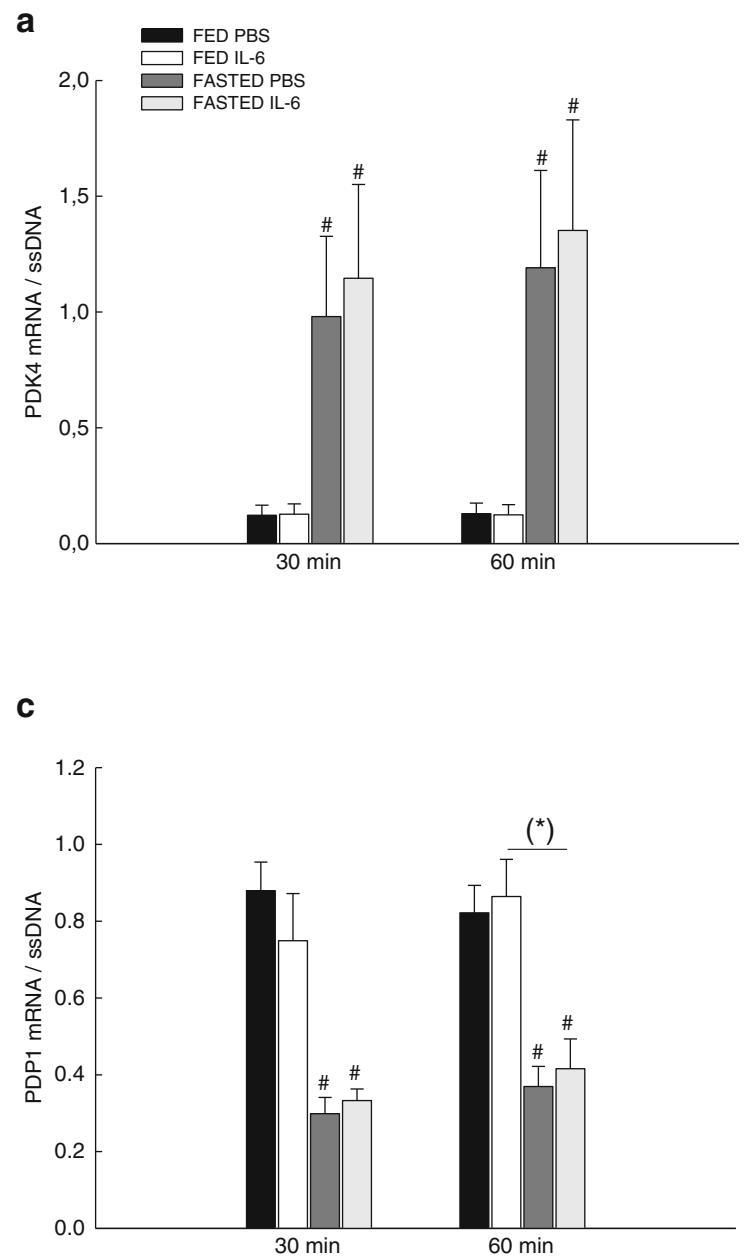

Fig. 5 mRNA and protein content of PDK4 and PDP1. PDK4 mRNA (a), PDK4 protein content (b), PDP1 mRNA (c), and PDP1 protein content (d) in skeletal muscle of fed (FED) and fasted (FASTED) mice 30 and $60 \mathrm{~min}$ after a single injection of either PBS or rmIL-6. Values are means \pm SE; $n=8$.
IL-6 injection in the present study was similar to the increase reported after a single exercise bout in mice [20], shows that the obtained IL-6 levels are at a physiologically relevant level. Furthermore, the increase in phosphorylation of the IL-6 signaling marker STAT3 in skeletal muscle in the current study demonstrates that IL-6 elicited an intracellular response in skeletal muscle at the investigated time points. Together this suggests that the present experimental setting can be used as a model to investigate the isolated effects of IL- 6 on PDH regulation in skeletal muscle during exercise. In addition, the pronounced fasting-induced decrease in muscle glycogen and plasma glucose concentration shows that the fasted mice were severely metabolically challenged. This provides a model to investigate the potential impact of the metabolic state for IL-6mediated effects on PDH regulation in skeletal muscle.

The observation that IL-6 downregulated PDHa activity in skeletal muscle in the fed state is in accordance with the

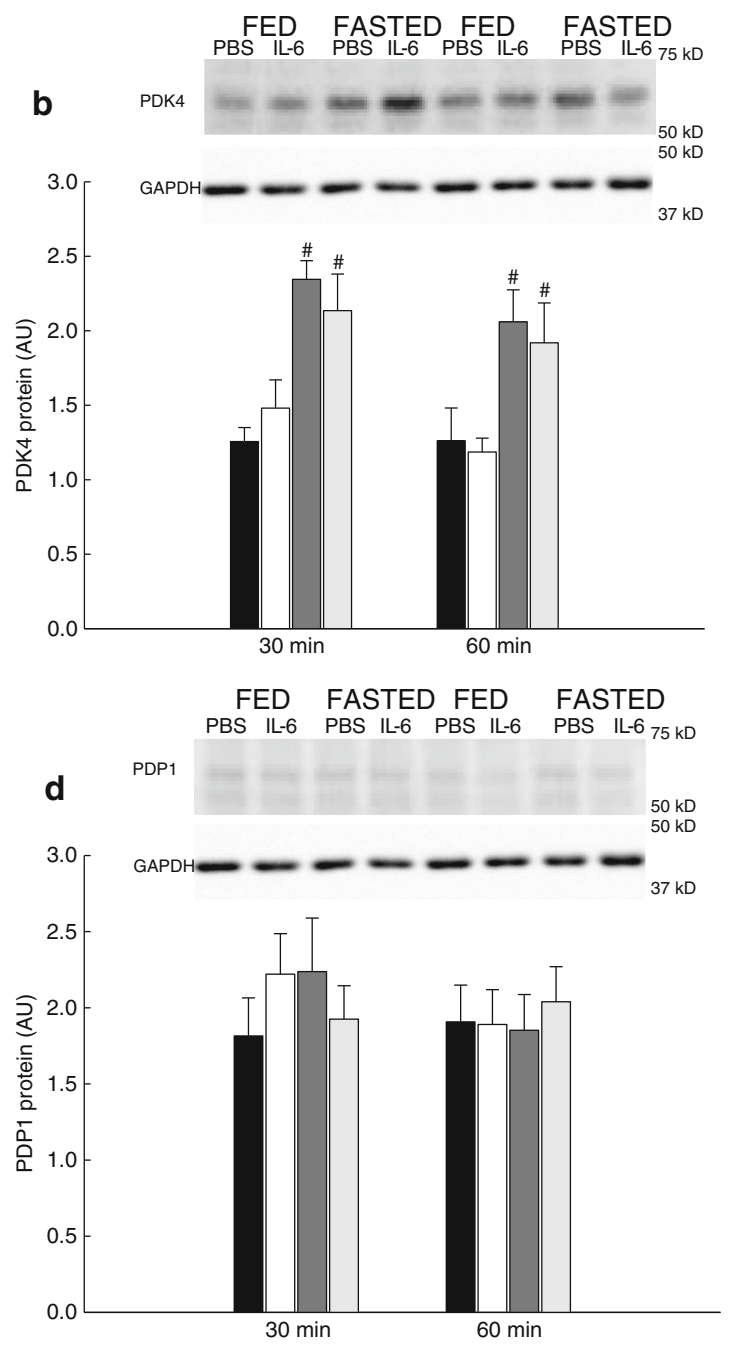

$* P<0.05$, significantly different from PBS within given condition and time point; $\# P<0.05$, significantly different from FED within given treatment and time point. Symbols within parentheses indicate a statistical tendency, $0.05 \leq$ $P<0.1$. Line indicates an overall effect 

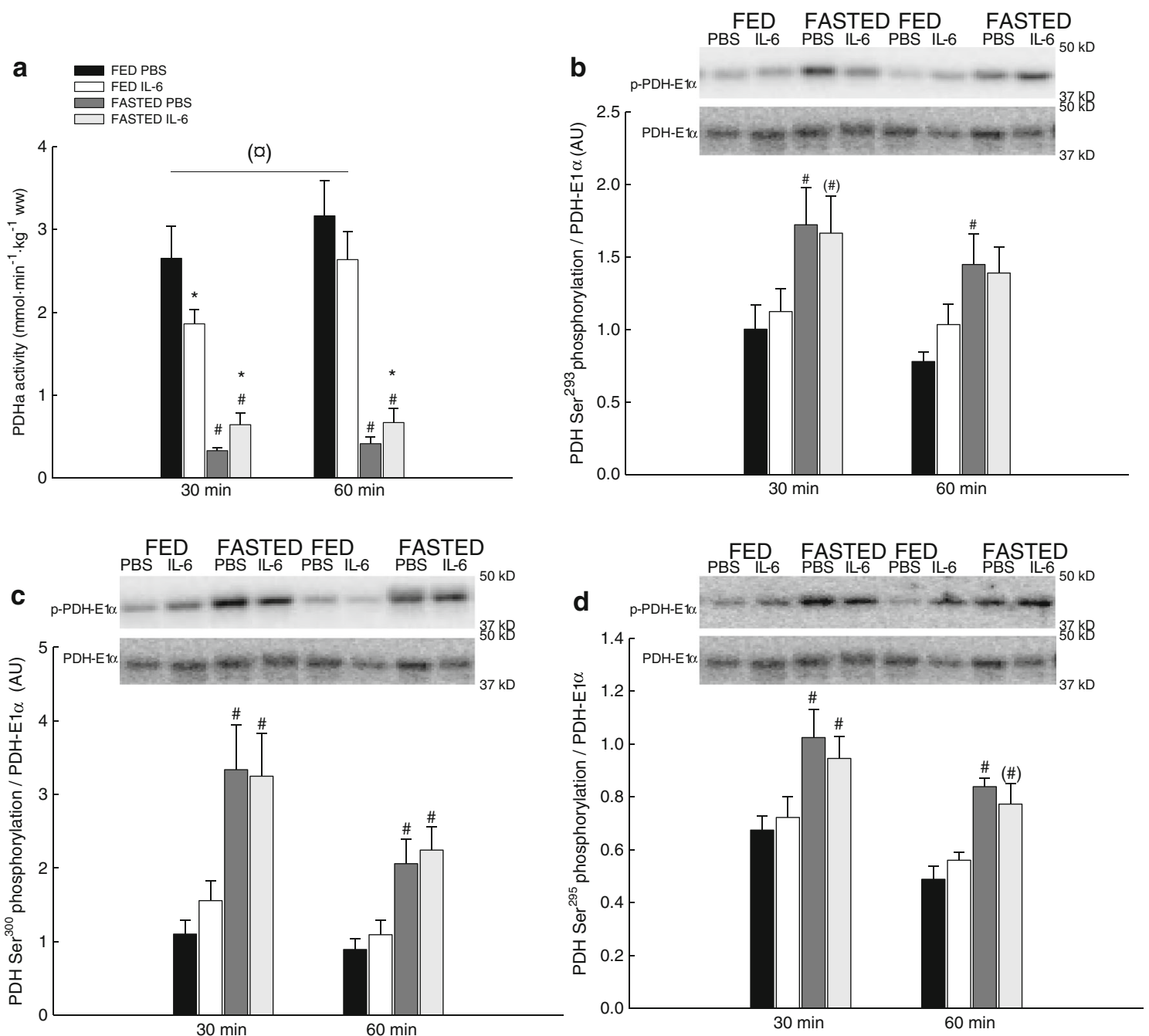

Fig. 6 PDHa activity and phosphorylation of PDH. PDHa activity (millimoles per minute per kilogram) (a), $\mathrm{PDH} \mathrm{Ser}{ }^{293}$ phosphorylation (b), PDH Ser ${ }^{300}$ phosphorylation (c), and PDH Ser ${ }^{295}$ phosphorylation (d) in skeletal muscle of fed (FED) and fasted (FASTED) mice 30 and $60 \mathrm{~min}$ after a single injection of either PBS or rmIL- 6 . Values are means \pm SE;

$n=8 . * P<0.05$, significantly different from PBS within given condition and time point; $\# P<0.05$, significantly different from FED within given treatment and time point; $\square 0.05 \leq P<0.1$, tendency for a difference between IL-6 and PBS. Symbols within parentheses indicate a statistical tendency $0.05 \leq P<0.1$. Line indicates an overall effect

previously shown IL-6-induced fat oxidation [35, 42] and suggests that IL-6 may contribute to regulating substrate choice during exercise towards increased skeletal muscle fat oxidation in part by regulating PDH. The previous observation that an IL-6 injection increased AMPK phosphorylation in rat skeletal muscle suggests that AMPK may be mediating IL-6-induced regulation [13]. Furthermore, AMPK $\alpha 2$ knockout $(\mathrm{KO})$ mice have been reported to exhibit an enhanced exercised-induced increase in PDHa activity [17] and the AMPK activator AICAR has been shown to increase PDK4 mRNA in skeletal muscle [11]. Together this suggests that IL6 mediates effects on PDH via AMPK. However, the present observation that AMPK and ACC phosphorylations were unaffected by IL-6 injections in the fed state does not support that AMPK was directly involved in the observed IL-6induced reduction in PDHa activity in the fed state.

The present findings that IL-6 elicited an increase in skeletal muscle PDHa activity in the fasted state, despite the IL-6induced downregulation in the fed state, indicate that the metabolic status influences the impact of IL-6 on PDH regulation. As IL-6 injections in the fasted state were associated with increased AMPK and ACC phosphorylation at $60 \mathrm{~min}$, it is possible that AMPK was involved in the IL-6-mediated $\mathrm{PDH}$ regulation at this time point. However, this potential effect of AMPK on PDH is opposite of the apparent AMPKmediated suppression of the exercise-induced PDHa activation, as suggested from the more marked exercise-induced increase in PDHa activity in AMPK $\alpha 2 \mathrm{KO}$ than wild-type (WT) mice [17]. However, the AMPK $\alpha 2 \mathrm{KO}$ mice in the previous study had lower muscle glycogen and plasma glucose after exercise than WT [17]. Therefore, the more marked $\mathrm{PDH}$ activation in AMPK $\alpha 2 \mathrm{KO}$ mice may not be due to the 
lack of AMPK, but rather that the AMPK $\alpha 2 \mathrm{KO}$ mice were more metabolically challenged than WT as also suggested in the previous study $[17,25]$. Furthermore, as low muscle glycogen has been suggested to enhance exercise-induced IL-6 expression and release from skeletal muscle [12] the more marked PDHa activation in the AMPK $\alpha 2 \mathrm{KO}$ mice in the previous study [17] may have been due to increased IL-6 levels rather than lack of AMPK. This possibility is supported by the previous finding that AICAR incubation elicited a higher IL-6 release from AMPK kinase dead mouse muscle than WT muscle [7] and is also in line with the present IL-6mediated increase in PDHa activity in the fasted state. In addition, the present findings that IL- 6 injection tended to reduce p 38 protein content in the fasted state may suggest that p38 potentially have contributed to the observed IL-6-induced increase in PDHa activity, because increased p38 phosphorylation has been associated with decreased PDHa activity in cardiomyocytes [29]. Of notice, the IL-6-induced downregulation of p38 protein only 30 and 60 min after injection is surprisingly fast and indicates that IL-6 either inhibits p38 synthesis or increases degradation. While a previous study has shown that IL-6 regulates p38 phosphorylation in skeletal muscle [40], no previous studies have to our knowledge reported IL-6-mediated regulation of p38 protein. However, it may be speculated that IL- 6 mediates the regulation of p38 mRNA targeting miRNA's leading to reduced translation of p38, but this remains to be determined.

As PDHa activity is known to be regulated by changes in NADH/NAD+, ATP/ADP, and acetyl CoA/acetyl [9, 24, 30], it may be speculated that IL-6 has mediated effects via changes in one of these ratios. Indeed a previous study has shown that IL-6 incubation of rat EDL decreased the ATP concentration and elevated the AMP concentration suggesting that IL-6induced changes in nucleotides could play a role in the observed IL-6-mediated regulation of PDHa activity in the present study. An IL-6-induced decrease in ATP and increase in AMP concentrations would be expected to be associated with an enhanced PDHa activity, which is in accordance with the changes observed in the fasted state in the present study. However, changes in ATP, ADP and AMP as well as $\mathrm{NADH} / \mathrm{NAD}+$ and acetyl $\mathrm{CoA} /$ acetyl are thought to exert effects on PDHa activity through changes in PDH-E1 $\alpha$ phosphorylation [10, 24]. Because IL-6 injections did not affect PDH-E1 $\alpha$ phosphorylation significantly neither in the fed nor the fasted state in the present study, changes in these parameters do not appear to be a likely mechanism for the observed IL-6-induced effects on PDH regulation.

It should be noted that IL-6 induced an increase in PDHa activity when PDHa activity was at a very low level due to the fasting conditions. This means that the PDHa activity after IL6 injections in the fasted state still was much lower than the level of PDHa activity after IL-6 induced downregulation of $\mathrm{PDH}$ in the fed state. The mechanism behind such a switch is unknown and additional studies are needed to answer this. The observations that PDHa activity, PDH-E1 $\alpha$ phosphorylation, PDK4 and PDP1 mRNA, as well as PDK4 protein were markedly changed by fasting in the present study are in accordance with previous studies [27, 28]. This shows that differences could be detected at the mRNA, protein phosphorylation, and activity level. Furthermore, the finding that fasting elicited $90 \%$ reduction in PDHa activity in PBS, while IL-6 injection only resulted in a $30 \%$ reduction demonstrates that the effect of $18 \mathrm{~h}$ of fasting is much more marked than a single IL-6 injection. This may indicate that IL-6 only contributes to the regulation of $\mathrm{PDH}$ for example by sensitizing PDHa to the metabolic needs of the cell. However, it may also be worth noting that the magnitude of reduction in $\mathrm{PDHa}$ activity in response to IL-6 injection is quite similar to the reduction previously reported in the exercise-induced increase in PDHa activity in human skeletal muscle, when muscle glycogen had been lowered prior to exercise [15]. This makes it possible that an enhanced IL-6 release contributed to the smaller exercise-induced increase in PDHa activity when muscle glycogen was reduced in the previous study [15]. Moreover, the similar magnitude of change in the present study and the previous human study indicates that the observed change in PDHa activity with IL-6 injections is similar to changes observed in a physiological setting in humans [15].

$\mathrm{PDH}-\mathrm{E} 1 \alpha$ phosphorylation is known to be the dominant regulatory mechanism determining $\mathrm{PDHa}$ activity. The unchanged PDH-E1 $\alpha$ phosphorylation with IL-6 injection in the present study indicates that the observed changes in PDHa activity was not due to changes in phosphorylation level. Such discrepancy between PDHa activity and PDH-E1 $\alpha$ phosphorylation has previously been reported in resting human and mouse skeletal muscle [14, 25], although the previous studies observed changes in $\mathrm{PDH}-1 \mathrm{E} \alpha$ phosphorylation without changes in PDHa activity. As effects of PDK and PDP expression and/or activity would be expected to influence the phosphorylation level of $\mathrm{PDH}-\mathrm{E} 1 \alpha$, these $\mathrm{PDH}$ regulatory proteins do not seem to be in play in the IL-6-mediated effects. This suggestion is in line with the unaffected PDK4 and PDP1 protein level with a single IL-6 injection. Furthermore, the unchanged plasma glucose concentration and unchanged muscle glycogen in the fed state upon IL-6 injection (although an overall difference was observed for muscle glycogen) indicate that IL-6 did not change the carbohydrate availability in the fed state. Thus, it seems unlikely that changes in the metabolic state have contributed to the observed downregulation of PDHa activity. It may therefore be speculated that IL-6 has elicited alternative mechanisms like changes in acetylation state, because several acetylation sites have been identified on PDH [8].

Based on the previous findings that reduced muscle glycogen has been shown to enhance IL-6 transcription in human skeletal muscle [12] it may be expected that fasting would 
elevate muscle IL-6 mRNA levels. However, the finding that a fasting-induced elevation in IL-6 mRNA only was observed in IL-6 injected mice suggests that low glycogen is not sufficient to increase IL-6 mRNA, and that IL-6 exerts a positive feedback on the expression of IL- 6 when muscle glycogen levels are low. In addition, the IL-6 induced intracellular signaling observed both in the fed and fasted state while IL6 mRNA only increased significantly in the fasted state in the present study, may suggest that an IL-6-mediated effect on IL6 expression requires a factor which is only available when muscle glycogen is low. As p38 has been implicated in regulating IL-6 expression [36] the observed fasting-induced increase in $\mathrm{p} 38$ protein content may have contributed to the elevated IL-6 mRNA. However, the observed reduction in p38 protein content with IL-6 injection does not support this possibility. Hence, the mechanism behind the fasting-induced increase in skeletal muscle IL-6 mRNA only when IL-6 was injected remains to be determined.

In conclusion, a single IL-6 injection reduces PDHa activity in mouse skeletal muscle in the fed state and increases PDHa activity in the fasted state. This suggests that IL-6-mediated PDH regulation contributes to regulating substrate choice, but that the metabolic state determines the outcome. IL-6 appears to regulate PDHa activity without clear changes in PDH-E1 $\alpha$ phosphorylation and AMPK and p38 may be involved in the IL-6-mediated PDH regulation in the fasted state.

Acknowledgments This study was funded by the Danish Medical Research Council for Independent Research and the Novo nordisk Foundation. We would also like to thank Prof. Graham Hardy (Dundee University, Dundee, U.K) for providing the PDH phospho specific, PDK4 and PDP1 antibodies. Centre of Inflammation and Metabolism, (CIM) is supported by a grant from the Danish National Research Foundation (\# 02-512-55).

Open Access This article is distributed under the terms of the Creative Commons Attribution License which permits any use, distribution, and reproduction in any medium, provided the original author(s) and the source are credited.

\section{References}

1. Al-Khalili L, Bouzakri K, Glund S, Lonnqvist F, Koistinen HA, Krook A (2006) Signaling specificity of interleukin-6 action on glucose and lipid metabolism in skeletal muscle. Mol Endocrinol 20:3364-3375

2. Behal RH, Buxton DB, Robertson JG, Olson MS (1993) Regulation of the pyruvate dehydrogenase multienzyme complex. Annu Rev Nutr 13:497-520

3. Cederblad G, Carlin JI, Constantin-Teodosiu D, Harper P, Hultman E (1990) Radioisotopic assays of CoASH and carnitine and their acetylated forms in human skeletal muscle. Anal Biochem 185:274-278

4. Chomczynski P, Sacchi N (1987) Single-step method of RNA isolation by acid guanidinium thiocyanate-phenol-chloroform extraction. Anal Biochem 162:156-159
5. Constantin-Teodosiu D, Cederblad G, Hultman E (1991) A sensitive radioisotopic assay of pyruvate dehydrogenase complex in human muscle tissue. Anal Biochem 198:347-351

6. Glund S, Deshmukh A, Long YC, Moller T, Koistinen HA, Caidahl K, Zierath JR, Krook A (2007) Interleukin-6 directly increases glucose metabolism in resting human skeletal muscle. Diabetes 56: $1630-1637$

7. Glund S, Treebak JT, Long YC, Barres R, Viollet B, Wojtaszewski JF, Zierath JR (2009) Role of adenosine 5'-monophosphate-activated protein kinase in interleukin- 6 release from isolated mouse skeletal muscle. Endocrinology 150:600-606

8. Gnad F, Gunawardena J, Mann M (2011) PHOSIDA 2011: the posttranslational modification database. Nucleic Acids Res 39: D253-D260

9. Harris RA, Bowker-Kinley MM, Huang B, Wu P (2002) Regulation of the activity of the pyruvate dehydrogenase complex. Adv Enzym Regul 42:249-259

10. Howlett RA, Parolin ML, Dyck DJ, Hultman E, Jones NL, Heigenhauser GJ, Spriet LL (1998) Regulation of skeletal muscle glycogen phosphorylase and PDH at varying exercise power outputs. Am J Physiol 275:R418-R425

11. Jorgensen SB, Wojtaszewski JF, Viollet B, Andreelli F, Birk JB, Hellsten Y, Schjerling P, Vaulont S, Neufer PD, Richter EA, Pilegaard H (2005) Effects of alpha-AMPK knockout on exerciseinduced gene activation in mouse skeletal muscle. FASEB J 19: $1146-1148$

12. Keller C, Steensberg A, Pilegaard H, Osada T, Saltin B, Pedersen BK, Neufer PD (2001) Transcriptional activation of the IL-6 gene in human contracting skeletal muscle: influence of muscle glycogen content. FASEB J 15:2748-2750

13. Kelly M, Gauthier MS, Saha AK, Ruderman NB (2009) Activation of AMP-activated protein kinase by interleukin-6 in rat skeletal muscle: association with changes in cAMP, energy state, and endogenous fuel mobilization. Diabetes 58:1953-1960

14. Kiilerich K, Adser H, Jakobsen AH, Pedersen PA, Hardie DG, Wojtaszewski JF, Pilegaard H (2010) PGC-1alpha increases PDH content but does not change acute PDH regulation in mouse skeletal muscle. Am J Physiol Regul Integr Comp Physiol 299:R1350-R1359

15. Kiilerich K, Gudmundsson M, Birk JB, Lundby C, Taudorf S, Plomgaard P, Saltin B, Pedersen PA, Wojtaszewski JF, Pilegaard H (2010) Low muscle glycogen and elevated plasma free fatty acid modify but do not prevent exercise-induced PDH activation in human skeletal muscle. Diabetes 59:26-32

16. Kiilerich K, Ringholm S, Bienso RS, Fisher JP, Iversen N, van HG, Wojtaszewski JF, Saltin B, Lundby C, Calbet JA, Pilegaard H (2011) Exercise-induced pyruvate dehydrogenase activation is not affected by 7 days of bed rest. J Appl Physiol 111:751-757

17. Klein DK, Pilegaard H, Treebak JT, Jensen TE, Viollet B, Schjerling P, Wojtaszewski JF (2007) Lack of AMPKalpha2 enhances pyruvate dehydrogenase activity during exercise. Am J Physiol Endocrinol Metab 293:E1242-E1249

18. Lowry OH, Passonneau JV (1972) A flexible system of enzymatic analysis. Academic, New York

19. Lundby C, Nordsborg N, Kusuhara K, Kristensen KM, Neufer PD, Pilegaard H (2005) Gene expression in human skeletal muscle: alternative normalization method and effect of repeated biopsies. Eur J Appl Physiol 95:351-360

20. Nedachi T, Fujita H, Kanzaki M (2008) Contractile C2C12 myotube model for studying exercise-inducible responses in skeletal muscle. Am J Physiol Endocrinol Metab 295:E1191-E1204

21. Ostrowski K, Rohde T, Zacho M, Asp S, Pedersen BK (1998) Evidence that interleukin-6 is produced in human skeletal muscle during prolonged running. J Physiol 508(Pt 3):949-953

22. Passonneau JV, Lauderdale VR (1974) A comparison of three methods of glycogen measurement in tissues. Anal Biochem 60: $405-412$ 
23. Pedersen BK, Febbraio M (2005) Muscle-derived interleukin-6 - a possible link between skeletal muscle, adipose tissue, liver, and brain. Brain Behav Immun 19:371-376

24. Peters SJ (2003) Regulation of PDH activity and isoform expression: diet and exercise. Biochem Soc Trans 31:1274-1280

25. Pilegaard H, Birk JB, Sacchetti M, Mourtzakis M, Hardie DG, Stewart G, Neufer PD, Saltin B, van HG, Wojtaszewski JF (2006) PDH-Elalpha dephosphorylation and activation in human skeletal muscle during exercise: effect of intralipid infusion. Diabetes 55 : 3020-3027

26. Pilegaard H, Ordway GA, Saltin B, Neufer PD (2000) Transcriptional regulation of gene expression in human skeletal muscle during recovery from exercise. Am J Physiol Endocrinol Metab 279:E806-E814

27. Pilegaard H, Osada T, Andersen LT, Helge JW, Saltin B, Neufer PD (2005) Substrate availability and transcriptional regulation of metabolic genes in human skeletal muscle during recovery from exercise. Metabolism 54:1048-1055

28. Pilegaard H, Saltin B, Neufer PD (2003) Effect of short-term fasting and refeeding on transcriptional regulation of metabolic genes in human skeletal muscle. Diabetes 52:657-662

29. Puthanveetil P, Wang Y, Wang F, Kim MS, Abrahani A, Rodrigues B (2010) The increase in cardiac pyruvate dehydrogenase kinase- 4 after short-term dexamethasone is controlled by an Akt-p38-forkhead box other factor-1 signaling axis. Endocrinology 151:2306-2318

30. Putman CT, Spriet LL, Hultman E, Dyck DJ, Heigenhauser GJ (1995) Skeletal muscle pyruvate dehydrogenase activity during acetate infusion in humans. Am J Physiol 268:E1007-E1017

31. Putman CT, Spriet LL, Hultman E, Lindinger MI, Lands LC, McKelvie RS, Cederblad G, Jones NL, Heigenhauser GJ (1993) Pyruvate dehydrogenase activity and acetyl group accumulation during exercise after different diets. Am J Physiol 265:E752-E760

32. Smith AC, Bruce CR, Dyck DJ (2005) AMP kinase activation with AICAR simultaneously increases fatty acid and glucose oxidation in resting rat soleus muscle. J Physiol 565:537-546
33. St Amand TA, Spriet LL, Jones NL, Heigenhauser GJ (2000) Pyruvate overrides inhibition of PDH during exercise after a lowcarbohydrate diet. Am J Physiol Endocrinol Metab 279:E275-E283

34. Steensberg A, van HG, Osada T, Sacchetti M, Saltin B, Klarlund PB (2000) Production of interleukin-6 in contracting human skeletal muscles can account for the exercise-induced increase in plasma interleukin-6. J Physiol 529(Pt 1):237-242

35. van HG, Steensberg A, Sacchetti M, Fischer C, Keller C, Schjerling P, Hiscock N, Moller K, Saltin B, Febbraio MA, Pedersen BK (2003) Interleukin-6 stimulates lipolysis and fat oxidation in humans. J Clin Endocrinol Metab 88:3005-3010

36. Vanden Berghe W, Vermeulen L, De WG, De BK, Boone E, Haegeman G (2000) Signal transduction by tumor necrosis factor and gene regulation of the inflammatory cytokine interleukin-6. Biochem Pharmacol 60:1185-1195

37. Ward GR, Sutton JR, Jones NL, Toews CJ (1982) Activation by exercise of human skeletal muscle pyruvate dehydrogenase in vivo. Clin Sci (Lond) 63:87-92

38. Watt MJ, Heigenhauser GJ, Dyck DJ, Spriet LL (2002) Intramuscular triacylglycerol, glycogen and acetyl group metabolism during $4 \mathrm{~h}$ of moderate exercise in man. J Physiol 541:969-978

39. Watt MJ, Heigenhauser GJ, LeBlanc PJ, Inglis JG, Spriet LL, Peters SJ (2004) Rapid upregulation of pyruvate dehydrogenase kinase activity in human skeletal muscle during prolonged exercise. J Appl Physiol 97:1261-1267

40. Weigert C, Dufer M, Simon P, Debre E, Runge H, Brodbeck K, Haring HU, Schleicher ED (2007) Upregulation of IL-6 mRNA by IL-6 in skeletal muscle cells: role of IL-6 mRNA stabilization and $\mathrm{Ca}^{2+}$-dependent mechanisms. Am J Physiol Cell Physiol 293:C1139-C1147

41. Whitten WK (1959) Occurrence of anoestrus in mice caged in groups. J Endocrinol 18:102-107

42. Wolsk E, Mygind H, Grondahl TS, Pedersen BK, van HG (2010) IL6 selectively stimulates fat metabolism in human skeletal muscle. Am J Physiol Endocrinol Metab 299:E832-E840

43. Wu P, Sato J, Zhao Y, Jaskiewicz J, Popov KM, Harris RA (1998) Starvation and diabetes increase the amount of pyruvate dehydrogenase kinase isoenzyme 4 in rat heart. Biochem J 329(Pt 1):197-201 